\title{
Communication
}

\section{A Long-Lasting Textile-Based Anatomically Realistic Head Phantom for Validation of EEG Electrodes}

\author{
Granch Berhe Tseghai ${ }^{1,2, *(\mathbb{D}}$, Benny Malengier ${ }^{1}\left(\mathbb{D}\right.$, Kinde Anlay Fante $^{2} \mathbb{C}$ and Lieva Van Langenhove ${ }^{1}$ \\ 1 Department of Materials, Textiles and Chemical Engineering, Ghent University, 9000 Gent, Belgium; \\ Benny.Malengier@UGent.be (B.M.); Lieva.VanLangenhove@UGent.be (L.V.L.) \\ 2 Jimma Institute of Technology, Jimma University, Jimma, Ethiopia; kinde.anlay@ju.edu.et \\ * Correspondence: GranchBerhe.Tseghai@UGent.be; Tel.: +32-465-570-635
}

check for updates

Citation: Tseghai, G.B.; Malengier, B.;

Fante, K.A.; Van Langenhove, L. A

Long-Lasting Textile-Based

Anatomically Realistic Head

Phantom for Validation of EEG

Electrodes. Sensors 2021, 21, 4658.

https://doi.org/10.3390/s21144658

Academic Editor: Yvonne Tran

Received: 10 May 2021

Accepted: 6 July 2021

Published: 7 July 2021

Publisher's Note: MDPI stays neutral with regard to jurisdictional claims in published maps and institutional affiliations.

Copyright: (c) 2021 by the authors. Licensee MDPI, Basel, Switzerland. This article is an open access article distributed under the terms and conditions of the Creative Commons Attribution (CC BY) license (https:// creativecommons.org/licenses/by/ $4.0 /)$.

\begin{abstract}
During the development of new electroencephalography electrodes, it is important to surpass the validation process. However, maintaining the human mind in a constant state is impossible which in turn makes the validation process very difficult. Besides, it is also extremely difficult to identify noise and signals as the input signals are not known. For that reason, many researchers have developed head phantoms predominantly from ballistic gelatin. Gelatin-based material can be used in phantom applications, but unfortunately, this type of phantom has a short lifespan and is relatively heavyweight. Therefore, this article explores a long-lasting and lightweight $(-91.17 \%)$ textile-based anatomically realistic head phantom that provides comparable functional performance to a gelatin-based head phantom. The result proved that the textile-based head phantom can accurately mimic body-electrode frequency responses which make it suitable for the controlled validation of new electrodes. The signal-to-noise ratio (SNR) of the textile-based head phantom was found to be significantly better than the ballistic gelatin-based head providing a $15.95 \mathrm{~dB} \pm 1.666$ $( \pm 10.45 \%)$ SNR at a $95 \%$ confidence interval.
\end{abstract}

Keywords: e-textile; head phantom; electroencephalography; conductive material

\section{Introduction}

Measuring the electrical activity in the brain, heart, muscles, etc., using electrodes to know the health condition of humans and/or animals is a common clinical practice. However, such electrodes have to be validated prior to being employed in clinical practices. For instance, PEDOT/PSS-based and silver-based electrocardiography (ECG) electrodes have been developed [1] to measure heart activity but a scientific validation was not performed as part of that research as ECG signals were different from person to person and even for the same person over time. Electroencephalography (EEG) measurements to monitor brain activity are much more variable with changes over seconds.

For the validation of EEG electrodes, it is, therefore, required to develop head phantoms as maintaining a constant brain activity is hardly possible. Hence, it is required to conduct a test in an environment as realistic as possible with a known ground truth of source location and brain activity. This can be performed via digital phantoms by modeling the propagation of the signal originating within the brain to the electrodes [2]. However, the studies via digital head phantom are hardly suited to mimic motion artifacts of a realistic EEG, electromagnetic interference noise generated by the power lines, and high power electronic equipment [3]. For that reason, many researchers have developed head phantoms predominantly from ballistic gelatin [4-8]. Gelatin-based materials are a good material to be used in phantom applications, but unfortunately, this type of phantom has a short life span [9] and is too heavyweight. Examples of gelatin-based head phantoms are shown in Figure 1. 


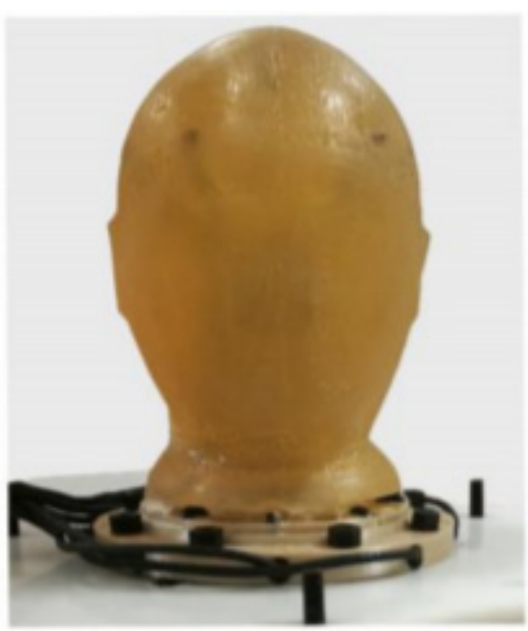

(a)

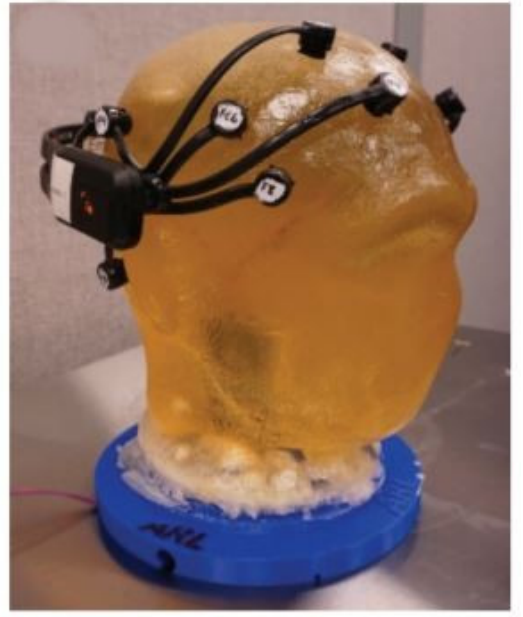

(b)

Figure 1. Examples of gelatin-based phantoms: (a) from [7]; (b) from [8].

Recently, Tsizin et al. developed a realistic head phantom mimicking the electromagnetic properties of the head where the internal volume of a human skull was filled with a conductive gel [10]. However, the lifetime of the phantom was only about a month. Other EEG head phantoms [11,12] prepared by casting were also introduced but still, the casting process is complicated, the phantoms are heavy and expensive. Therefore, developing a simple lightweight and long-lasting textile-based head phantom would be an important improvement.

The emergence of electrically conductive textiles led textile materials to a versatile application in the electronic and medical industries [13]. Electrically conductive textiles can be developed by different techniques and in different forms [14]. Moreover, the electrical and physical properties of the textile substrate can be easily controlled, and the required extent of stretchability, flexibility, and conductivity can be imparted by regulating the substrate, textile construction, and application of the conductive component. Therefore, this work explores the use of e-textiles for a head phantom.

\section{Materials and Methods}

\subsection{Head Phantoms Construction}

A textile-based head phantom was constructed by placing a bi-directional stretchy nylon/spandex (18:7) EeonTex conductive stretchable fabric (obtained from MANDU, Finland) over an anatomically realistic 3D-print polylactic acid (PLA) skull. The conductive fabric has a surface resistivity that can be custom-tuned for specific requirements in the range of $10^{4}$ to $10^{7} \Omega$ /square. To mimic the neurons, twenty (20) $3.5 \mathrm{~mm}$ stereo malemale dipole wires were installed underneath the conductive fabric per the 10-20 EEG placement system as shown in Figure 2a. Side to side, a gelatin-based head phantom was also constructed from $900 \mathrm{~g}$ gelatin, $40.5 \mathrm{~g}$ table salt, and $4.5 \mathrm{~L}$ demineralized water according to [15], for comparison. Thirty-seven (37) dipole wires were installed inside the ballistic gelatin as shown in Figure 2b. The skull, base-ring, inner-post, and guiding wires have been constructed from PLA using an FDM 3D printer at Ingegno Maker Space (Drongen, Belgium). The photographic images of the constructed textile and gelatin-based head phantoms and their components are shown in Figure 2a,b, respectively. 


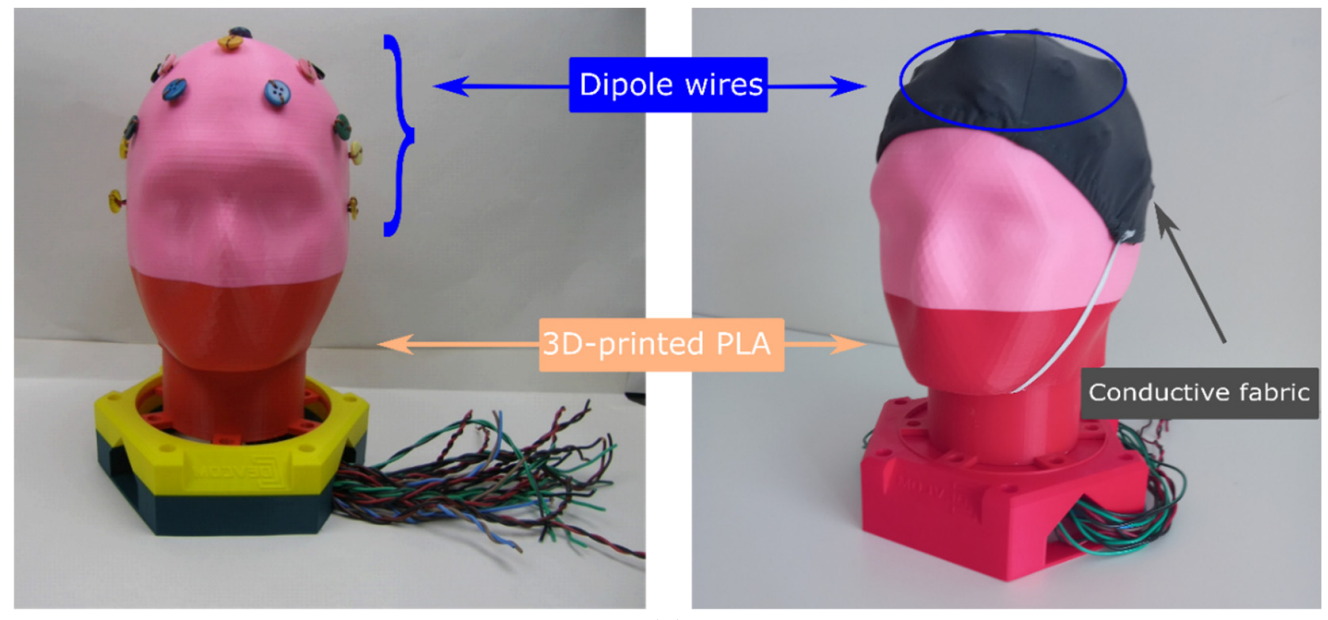

(a)

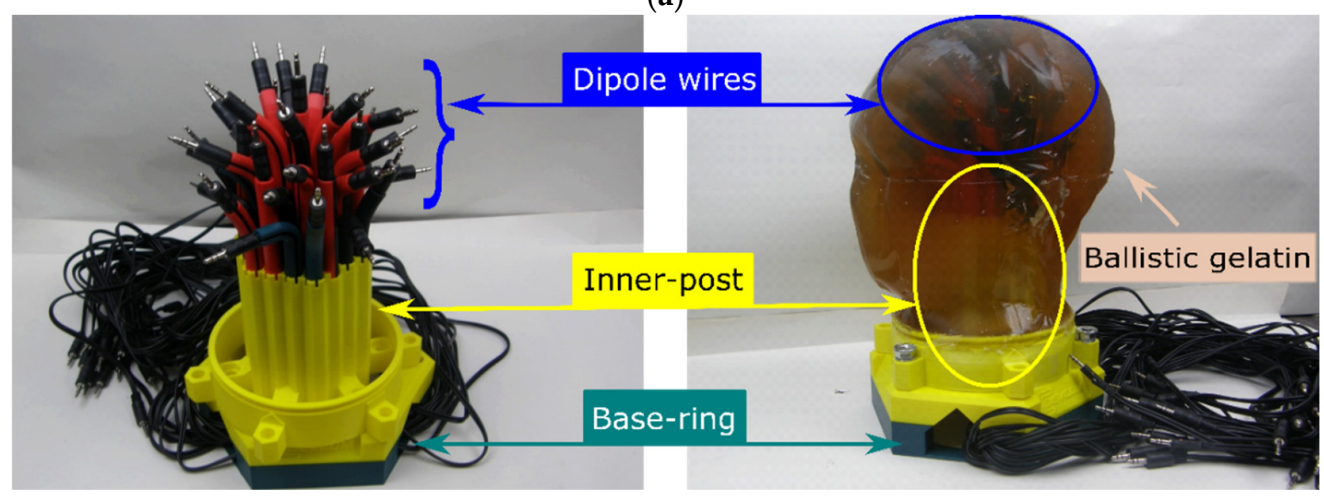

(b)

Figure 2. Head Phantom: (a) textile-based; (b) ballistic gelatin-based.

\subsection{Head Phantom Validation}

To validate the head phantoms, a synthetic sine wave $(360 \mathrm{mV}$ peak to peak voltage, $168 \mathrm{mV}$ maximum voltage, $-192 \mathrm{mV}$ minimum voltage, $9.925 \mathrm{~Hz}$ frequency) was generated using a function generator DDS Function Signal Generator and recorded with a handheld tablet digital oscilloscope (Micsig TO1104). This was then injected into the head phantoms as shown in Figure 3. To impersonate events, the electroencephalography (EEG) phantom signal parameters were set in the alpha wave range and the amplitude was varied with the function generator to mimic a neurological event.

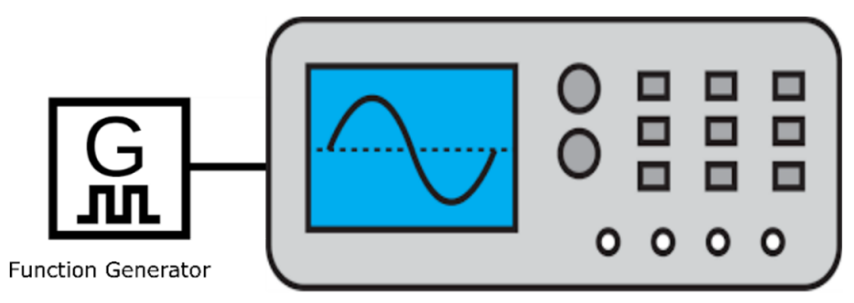

(a)

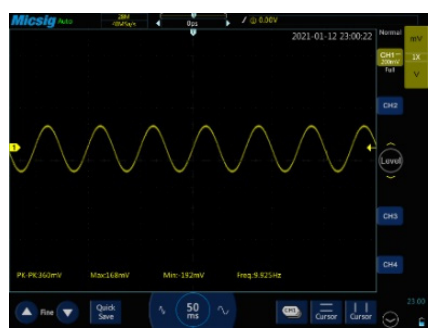

(b)

Figure 3. Synthetic sine wave generation: (a) wave generation setup using a function generator and digital oscilloscope; (b) the photographic image of the generated synthetic sine wave.

The head phantom replaces a real human head, and EEG electrodes can be attached as one would do on a human. In this test, the generated EEG wave was measured on both types of head phantoms using an active reusable snap $\mathrm{Ag} / \mathrm{AgCl}$ dry electrode connected to a Cyton biosensing Board (8-channels) of OpenBCI according to the setup in Figure 4. 

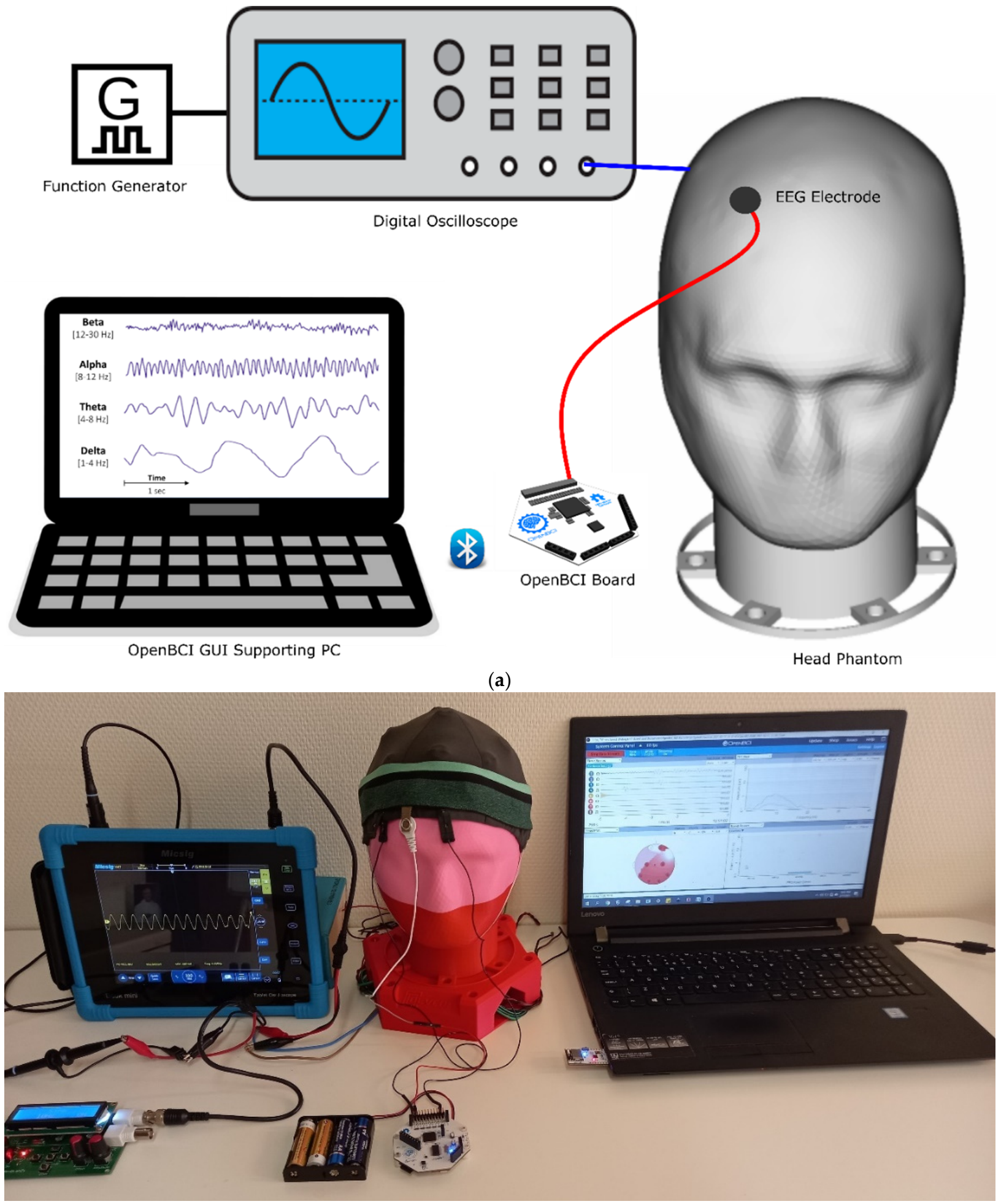

(b)

Figure 4. Measurement-setup: (a) schematic illustration; (b) actual.

\subsection{Phantom-to-Electrode Impedance}

The head phantom-to-electrode impedance was measured using a three-electrode configuration (reference, counter, and active electrodes), also with the Cyton Biosensing (OpenBCI) board and reusable snap $\mathrm{Ag} / \mathrm{AgCl}$ dry EEG electrodes to study the difference between the ballistic gelatin and textile-based head phantoms. The system was adopted 
from OpenBCI and was suggested to measure skin-to-electrode impedance as the OpenBCI Cython board has an installed ADS1299 to measure impedance. A $5 \mathrm{k} \Omega$ resistor is built into the OpenBCI board in series to each electrode and has to be taken into account. The ADS1299 has a feature called "Lead Off Detection" that can do the impedance measurement by injecting a known current into each electrode. A $6 \mathrm{nA}$ current is forced into the electrode line by a current source built into the ADS1299 [16], regardless of how much resistance or impedance there is between the current source and the ground (within reason). Hence, a $6 \mathrm{nA}$ current will be present through the electrode to the ground during this test. For this work, only the head phantoms were used, no humans. Therefore, the impedance was calculated using Equation (1), where the current is $6 \times 10^{-9}$ A. Then, the phantom-toelectrode impedance was analytically calculated.

$$
\text { Average Impedance }(\Omega)=\frac{\text { Average Voltage }(V)}{\text { Current }(I)}
$$

However, the average voltages collected during the test are in root mean square voltages (Vrms). Thus, the average voltage was calculated using Equation (2).

$$
\text { Average Voltage }=\frac{\text { Vrms } \times 2 \sqrt{2}}{\pi}=\frac{\text { Vrms }}{1.1107}
$$

Finally, the average impedance here is the series resistance of the head phantom-toelectrode interface and the $5 \mathrm{k} \Omega$ resistor built into the OpenBCI board. So, to obtain the actual impedance of just the phantom-to-electrode interface, one needs to subtract $5 \mathrm{k} \Omega$ from the average impedance as in Equation (3).

$$
\text { Actual Average Impedance }(\Omega)=\text { Average } \operatorname{Impedance}(\Omega)-5000
$$

\subsection{Signal Analysis}

The quality of signals collected was mathematically analyzed in terms of Signal-toNoise Ratio (SNR) using Equation (4). The peak-to-peak voltage signal is the synthetic peak-to-peak voltage injected from the digital oscilloscope to the head phantom and the peak-to-peak voltage signal is the difference between the injected and collected back peakto-peak voltage signal.

$$
\operatorname{SNR}(d B)=10 \log \left(\frac{\text { Peak to Peak Voltage Signal }}{\text { Peak to Peak Voltage Noise }}\right)
$$

The event-related spectral perturbation (ERSP) and inter-trial coherence (ITC) timefrequency measurements were then processed and analyzed via EEGLAB software that is treated as in Equation (5) according to spectral and coherence estimates on EEG recordings [17]. ITC is computed from single-trial EEG to reflect the temporal and spectral synchronization within EEG, explaining the extent to which underlying phase-locking occurs [17].

$$
\operatorname{ITC}(f, t)=\frac{1}{n} \sum_{k=1}^{n} \frac{F_{k}(f, t)}{F_{k}(f, t) \vee}
$$

where $F, t$ and $n$ denote frequency, time and amount of data, respectively.

\section{Results and Discussion}

The new textile-based head phantom has a much lighter weight than the gelatin-based i.e., 0.5 and $6 \mathrm{~kg}$, respectively. Therefore, the weight reduction is $91.67 \%$ which makes it more suitable for handling and moving from place to place. In addition, it is not delicate like the ballistic gelatin-based, where the shape of ballistic gelatin could be distorted and decays fast even when kept in a refrigerator. In our case, the gelatin-based head phantom begun decaying after a week of its construction which may also depend on the weather 
where it is placed during testing. In contrast, the textile-based head phantom does not decay at all.

\subsection{Phantom-to-Electrode Impedance}

The results in Table 1 indicate that the impedance of the textile-based head phantom is significantly lower with an f-ratio value of 2123.35 and a $p$-value of $<0.001$ at a $95 \%$ confidence interval according to one-way ANOVA. It is $1863 \Omega$ for the textile-based head phantom and $2297 \Omega$, so they are in the same operating range. For comparison, a skinto-electrode impedance measurement was performed on a human with the OpenBCI board and was found to be in the range of $3239.55 \Omega$ to $1991.09 \Omega$, which is in the same range as the textile-based head phantom. The lower impedance means the long-lasting and lightweight textile-based head phantom can collect somewhat better-quality signals than the gelatin-based head phantom which would make it preferable for validating EEG electrodes in particular and other bio-potential electrodes in general. The head phantom can also potentially be used during modeling and simulation work related to brain neurological activities.

Table 1. Head phantom to electrode impedance.

\begin{tabular}{cccccccc}
\hline \multirow{2}{*}{ Test } & \multirow{2}{*}{$\begin{array}{c}\text { Time } \\
\text { Counter (s) }\end{array}$} & \multicolumn{2}{c}{ Textile-Based Head Phantom } & \multicolumn{3}{c}{ Gelatin-Based Head Phantom } \\
\cline { 3 - 7 } & $\mathbf{V}_{\text {raw }}$ & $\mathbf{Z}_{\text {raw }}$ & $\mathbf{Z}_{\text {act }}$ & $\mathbf{V}_{\text {raw }}$ & $\mathbf{Z}_{\text {raw }}$ & Zact \\
\hline 1 & 30 & 41.18 & 6863 & 1863 & 43.93 & 7321 & 2321 \\
2 & 60 & 43.81 & 7301 & 2301 & 43.98 & 7330 & 2330 \\
3 & 90 & 42.66 & 7110 & 2110 & 44.54 & 7423 & 2423 \\
4 & 120 & 42.92 & 7153 & 2153 & 43.87 & 7311 & 2311 \\
5 & 150 & 43.13 & 7188 & 2188 & 42.49 & 7081 & 2081 \\
6 & 180 & 42.44 & 7073 & 2073 & 44.12 & 7353 & 2353 \\
7 & 210 & 41.33 & 6888 & 1888 & 43.72 & 7286 & 2286 \\
8 & 240 & 42.72 & 7120 & 2120 & 43.63 & 7271 & 2271 \\
& \multirow{2}{*}{ Mean } & $\mathbf{4 1 . 1 8}$ & $\mathbf{6 8 6 3}$ & $\mathbf{1 8 6 3}$ & $\mathbf{4 3 . 7 9}$ & $\mathbf{7 2 9 7}$ & $\mathbf{2 2 9 7}$ \\
\hline
\end{tabular}

$\mathrm{V}_{\text {raw }}=$ Raw Average Voltage $(\mu \mathrm{V}), \mathrm{Z}_{\mathrm{avg}}=$ Raw Average Impedance $(\Omega), \mathrm{Z}_{\mathrm{act}}=$ Actual Average Impedance $(\Omega)$.

\subsection{Electroencephalogram (EEG) Signal}

EEG is a term for the electrical signals of the brain [18] and was introduced by Hans Berger in 1929 [19]. Electrodes located outside (noninvasive brain-computer interface) of our brain, i.e., on the human scalp, are used to measure EEG. The frequency is the most common method for classifying EEG waveforms, to the point that EEG waves are denoted using Greek numerals based on their frequency spectrum. Delta (0.5 to $4 \mathrm{~Hz})$, theta (4 to $7 \mathrm{~Hz})$, alpha (8 to $12 \mathrm{~Hz})$, sigma $(12$ to $16 \mathrm{~Hz})$, and beta are the most widely studied waveforms (13 to $30 \mathrm{~Hz})$.

The textile-based head phantom allowed for the injection of well-defined synthetic waves using a digital oscilloscope, and collection of the EEG waveform using an OpenBCI board, strongly similar and matching to the gelatin-based. The EEG wave collected from the textile-based head phantom predominantly lays in the alpha band, the same as the injected sine wave. Whereas, from the ballistic gelatin, a very small theta band was observed where an injected band power was generated. From the EEG band powers in Figure 5, the noise in the textile-based head phantom was less, however, statistically, the root-mean-square voltages (Vrms) from the time series in Figure 5 in both phantoms were not significantly different at $95 \%$ of confidence interval according to one-way ANOVA. The frequency vs. FFT (Fast Fourier Transform) plot showed that the amplitude and frequencies were strongly similar and in the same range, in addition, the head plot was also quite similar. Therefore, this textile-based head phantom can potentially replace the gelatin-based head for validating EEG electrodes. 


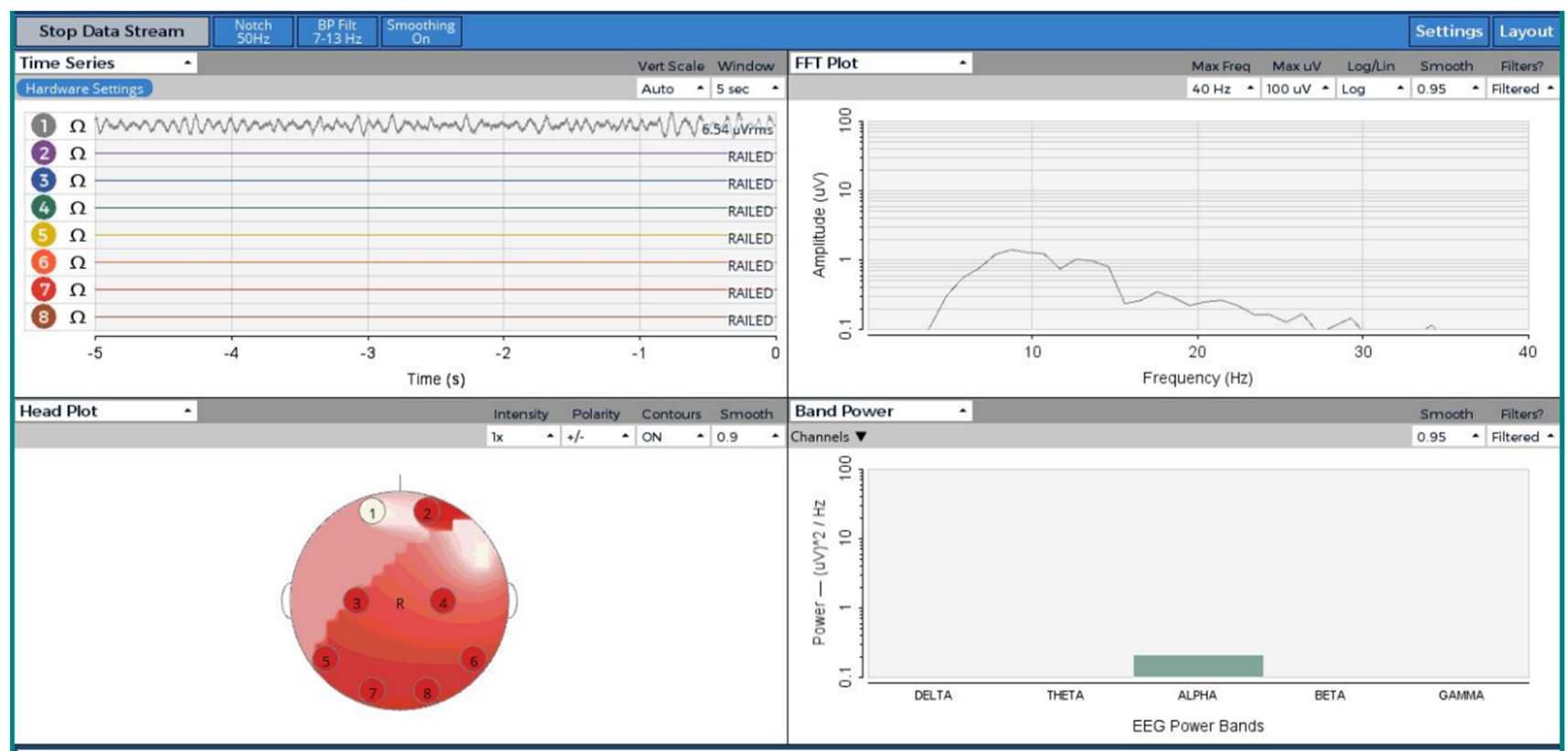

(a)

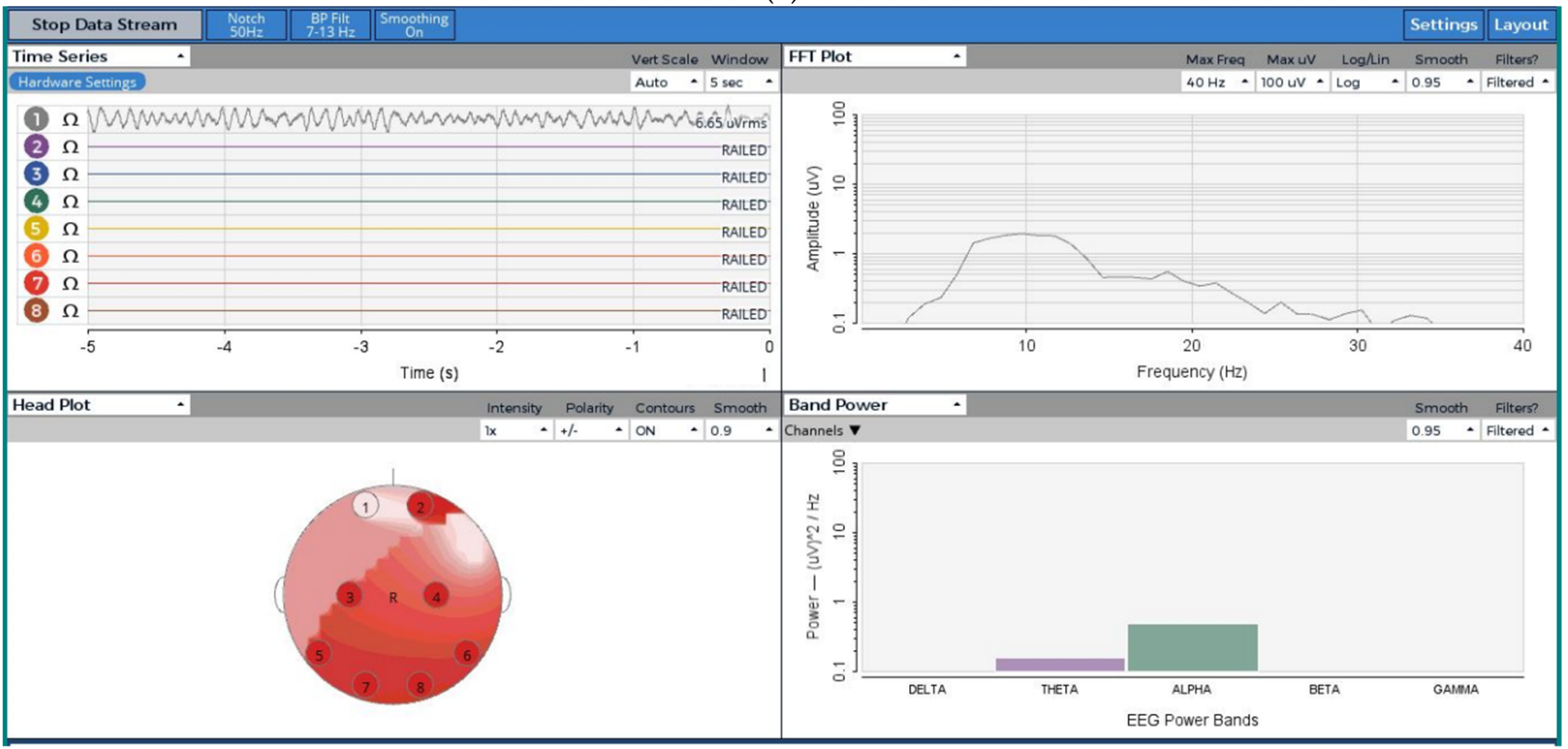

(b)

Figure 5. EEG signal from OpenBCI board: (a) textile-based head phantom; (b) gelatin-based head phantom.

\subsection{SNR Analysis}

From Table 2, the SNR of the textile-based head phantom was found to be significantly better than the gelatin-based one. The marginal error was $15.95 \mathrm{~dB} \pm 1.666( \pm 10.45 \%)$ with a $95 \%$ confidence interval. Therefore, textile-based head phantoms are preferable.

Table 2. Injected wave, acquired signal, and SNR of the head phantoms.

\begin{tabular}{|c|c|c|c|c|c|}
\hline & Wave & V Max (mV) & V Min (mV) & V Pk-Pk (mV) & SNR (dB) \\
\hline \multirow[t]{2}{*}{ Function generator } & Synthetic Signal & 168.00 & -192.00 & 360.00 & \\
\hline & Signal & 164.92 & -184.30 & 349.22 & \\
\hline \multirow{3}{*}{ Gelatin-based head phantom } & Noise & 3.08 & -7.701 & 10.78 & 15.1 \\
\hline & Signal/Noise & 0.054 & 0.024 & 0.032 & \\
\hline & Signal & 166.83 & -185.80 & 352.63 & \\
\hline \multirow[t]{2}{*}{ Textile-based head phantom } & Noise & 1.17 & -6.20 & 7.37 & 16.8 \\
\hline & Signal/Noise & 0.142 & 0.03 & 47.84 & \\
\hline
\end{tabular}




\subsection{Inter-Trial Coherence (ITC) and Event-Related Spectral Perturbation (ERSP)}

The frequency and time ranges are plotted on the y-axis and x-axis, respectively, and a color scale is used, with green representing non-significant ITC and red representing significant ITC at a $99 \%$ confidence interval. The averaged ERP response for that person (in blue) is plotted beneath each ITC plot. The ERP response amplitude scale for both phantoms is somewhat close in this study. From EEGLAB software analysis, the log power spectral density for both the CDE and TE was $\sim 90 \mathrm{~dB}$. However, the distribution of spectral powers was more uniform in the textile-based main phantom. The ITC and ERP plots of the textile-based and gelatin-based head phantoms are shown in Figure 6.
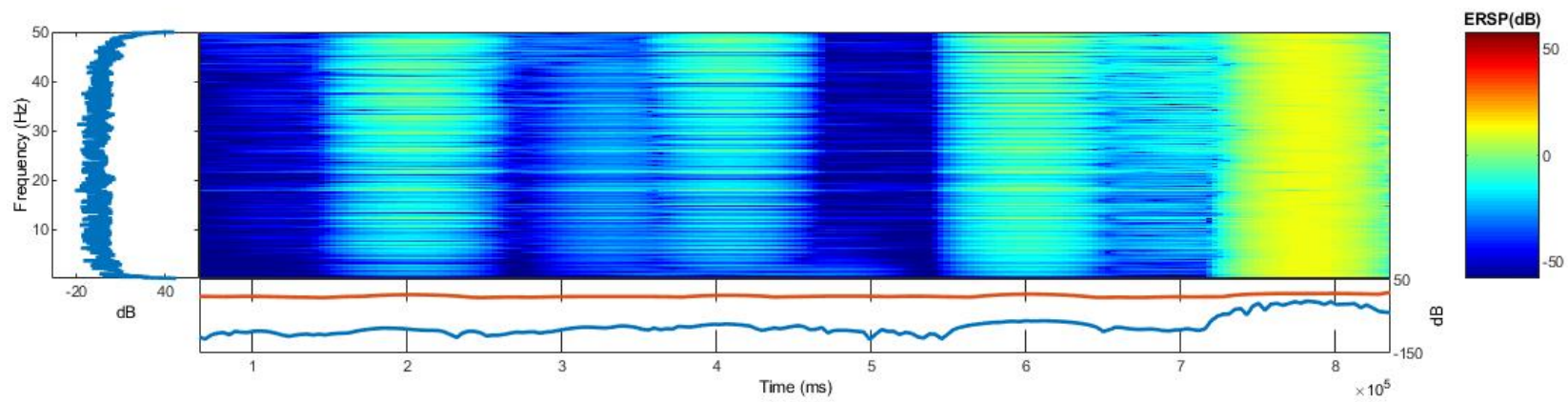

$\mathrm{dB}$

Time (ms)
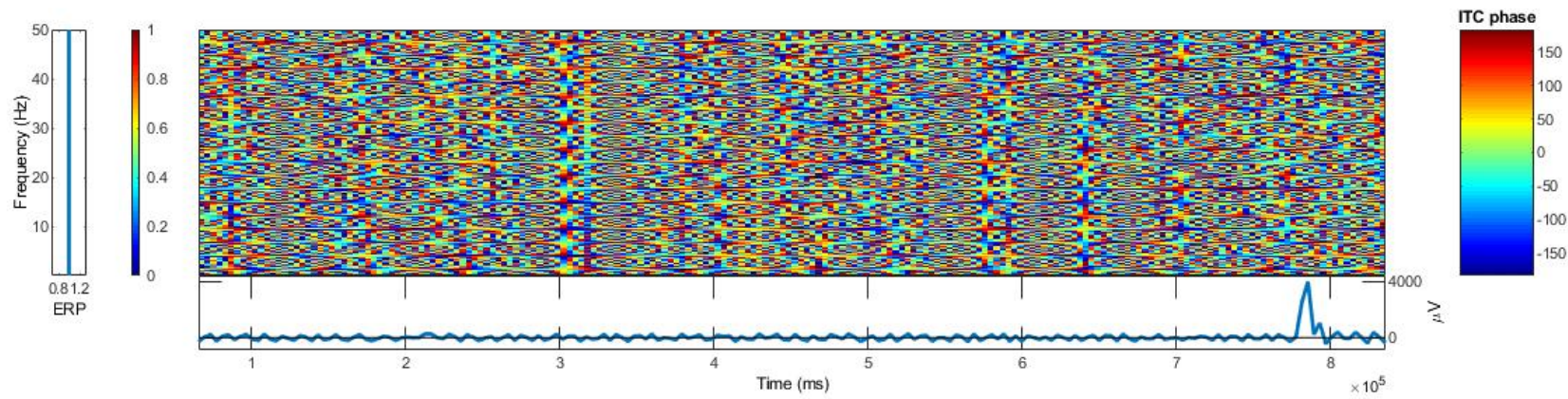

(a)
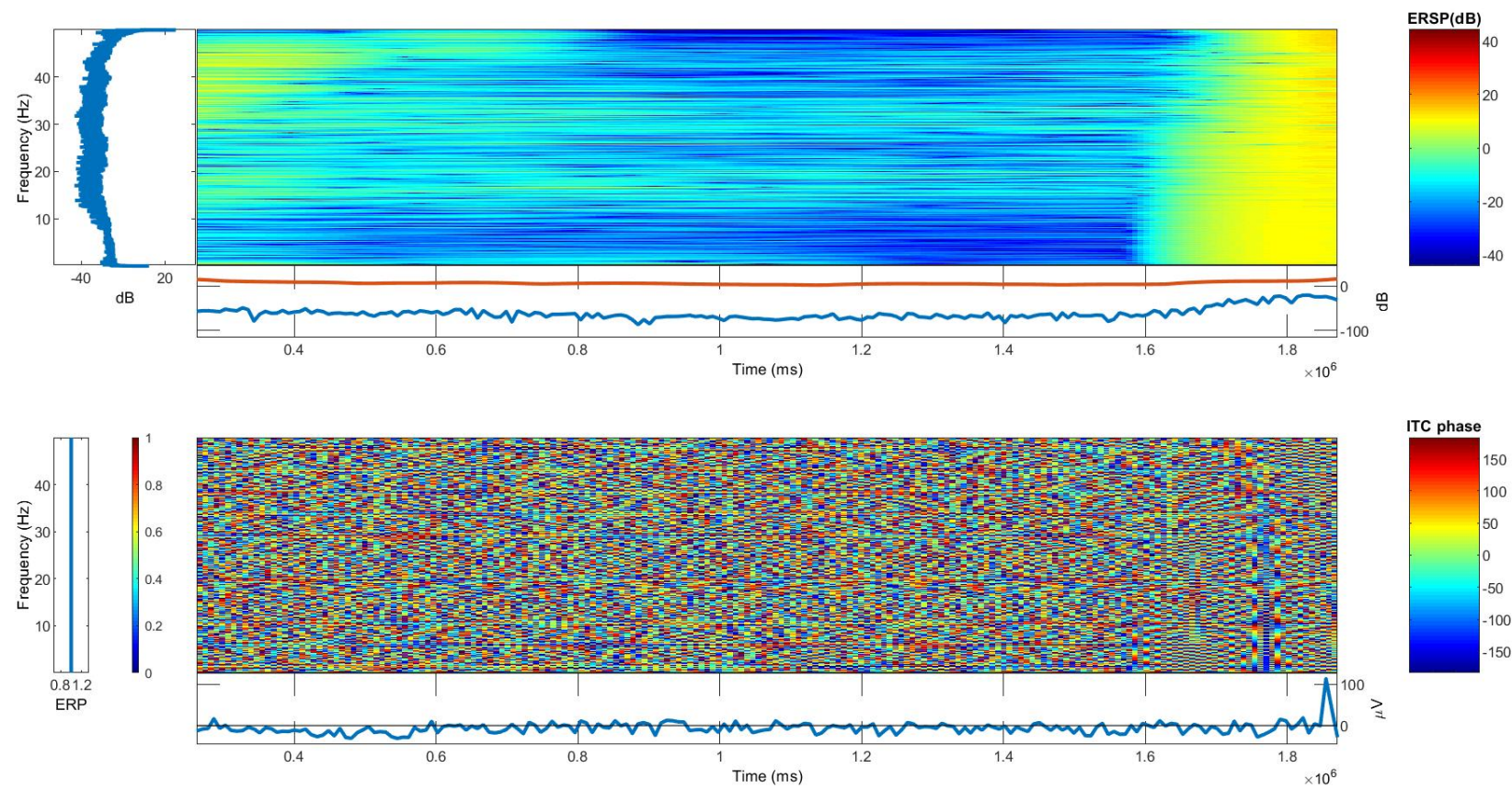

(b)

Figure 6. ITC and ERSP: (a) gelatin-based head phantom; (b) textile-based head phantom. 


\section{Conclusions}

Keeping the human brain constant is hardly possible. Therefore, anatomically realistic head phantoms should be used to validate bio-potential electrodes such as for an electroencephalogram (EEG). In this work, we explored a long-lasting and lightweight head phantom that allows synthetic wave injection and measuring at a performance similar to the commonly used ballistic gelatin-based head phantoms. It was found to perform similarly, and for some users even better than the gelatin-based one. While the textile-based phantom was designed for EEG, it can also be adapted to electrocardiogram, electromyogram, electrooculogram, and other related studies as well.

Author Contributions: Conceptualization, G.B.T.; methodology, G.B.T. and B.M.; validation, G.B.T.; formal analysis, G.B.T.; investigation, G.B.T.; resources, G.B.T. and B.M.; data curation, G.B.T.; writing—original draft preparation, G.B.T.; writing—review and editing, B.M.; visualization, G.B.T., B.M., K.A.F., and L.V.L.; project administration, K.A.F. and L.V.L.; funding acquisition, L.V.L. All authors have read and agreed to the published version of the manuscript.

Funding: This research and APC were funded by The research was funded by NASCERE and IUPEPPE projects and European Commission (Smartex Project), grant number 610465-EPP-1-2019-1EL-EPPKA2-CBHE-JP.

Institutional Review Board Statement: Not applicable.

Acknowledgments: The authors would like to express appreciation for the support of the NASCERE and IUPEPPE Projects sponsored with funds from the Ethiopian government and Smartex project funded with support from the European Commission. This publication reflects the views only of the authors, and the Ethiopian government and the European Commission cannot be held responsible for any use which may be made of the information contained therein. The authors would also like to thank the Ingegno Maker Space, Drongen, Belgium for the use of their makerlab and equipment in the creation of the 3D prints.

Conflicts of Interest: The authors declare no conflict of interest. The funders had no role in the design of the study; in the collection, analyses, or interpretation of data; in the writing of the manuscript, or in the decision to publish the results.

\section{References}

1. Tseghai, G.B.; Malengier, B.; Fante, K.A.; Nigusse, A.B.; Etana, B.B.; Van Langenhove, L. PEDOT:PSS/PDMS-Coated Cotton Fabric for ECG Electrode. In Proceedings of the IEEE International Conference on Flexible and Printable Sensors and Systems (FLEPS), Manchester, UK, 16 August 2020. [CrossRef]

2. Hallez, H.; Vanrumste, B.; Grech, R.; Muscat, J.; De Clercq, W.; Vergult, A.; D'Asseler, Y.; Camilleri, K.P.; Fabri, S.G.; Van Huffel, S.; et al. Review on Solving the Forward Problem in EEG Source Analysis. J. Neuroeng. Rehabil. 2007, 4, 46. [CrossRef] [PubMed]

3. Oliveira, A.S.; Schlink, B.R.; Hairston, W.D.; König, P.; Ferris, D.P. Induction and Separation of Motion Artifacts in EEG Data Using a Mobile Phantom Head Device. J. Neural Eng. 2016, 13, 036014. [CrossRef] [PubMed]

4. Kohli, S.; Casson, A.J. Removal of Gross Artifacts of Transcranial Alternating Current Stimulation in Simultaneous EEG Monitoring. Sensors 2019, 19, 190. [CrossRef] [PubMed]

5. Richardson, C.; Bernard, S.; Dinh, V.A. A Cost-Effective, Gelatin-Based Phantom Model for Learning Ultrasound-Guided Fine-Needle Aspiration Procedures of the Head and Neck. J. Ultrasound Med. 2015, 34, 1479-1484. [CrossRef] [PubMed]

6. Md Said, M.S.; Seman, N.; Sulaiman, N.R.; Abd Rahman, T. Modeling of Gelatin-Based Head Phantom Based on Its Electrical Properties for Wideband Microwave Imaging Application. Appl. Mech. Mater. 2015, 781, 608-611. [CrossRef]

7. Symeonidou, E.-R.; Nordin, A.; Hairston, W.; Ferris, D. Effects of Cable Sway, Electrode Surface Area, and Electrode Mass on Electroencephalography Signal Quality during Motion. Sensors 2018, 18, 1073. [CrossRef]

8. Owda, A.Y.; Casson, A.J. Electrical Properties, Accuracy, and Multi-Day Performance of Gelatine Phantoms for Electrophysiology. BioRxiv 2020. [CrossRef]

9. Said, M.S.M.; Seman, N. Preservation of Gelatin-Based Phantom Material Using Vinegar and Its Life-Span Study for Application in Microwave Imaging. IEEE Trans. Dielectr. Electr. Insul. 2017, 24, 528-534. [CrossRef]

10. Tsizin, E.; Mund, T.; Bronstein, A. Printable Anisotropic Phantom for EEG with Distributed Current Sources. In Proceedings of the IEEE International Symposium on Biomedical Imaging (ISBI), Washington, DC, USA, 4-7 April 2018.

11. Collier, T.J.; Kynor, D.B.; Bieszczad, J.; Audette, W.E.; Kobylarz, E.J.; Diamond, S.G. Creation of a Human Head Phantom for Testing of Electroencephalography Equipment and Techniques. IEEE Trans. Biomed. Eng. 2012, 59, 2628-2634. [CrossRef]

12. Audette, W.E.; Bieszczad, J.; Allen, L.V.; Diamond, S.G.; Kynor, D.B. Design and Demonstration of a Head Phantom for Testing of Electroencephalography (EEG) Equipment; Report number: TN-1113; Creare, Inc.: Hanover, NH, USA, 2020. [CrossRef] 
13. Tseghai, G.B.; Malengier, B.; Fante, K.A.; Van Langenhove, L. The Status of Textile-Based Dry EEG Electrodes. Autex Res. J. 2021, 21, 63-70. [CrossRef]

14. Tseghai, G.B.; Malengier, B.; Fante, K.A.; Nigusse, A.B.; Langenhove, L.V. Integration of Conductive Materials with Textile Structures, an Overview. Sensors 2020, 20, 6910. [CrossRef] [PubMed]

15. Yu, A.; Hairston, W.D. Open EEG Phantom. Available online: https:/ / osf.io/qrka2/ (accessed on 8 October 2020).

16. Texas Instruments. ADS1299-x Low-Noise, 4-, 6-, 8-Channel, 24-Bit, Analog-to-Digital Converter for EEG and Biopotential Measurements; Texas Instruments: Dallas, TX, USA, 2017.

17. Nash-Kille, A.; Sharma, A. Inter-Trial Coherence as a Marker of Cortical Phase Synchrony in Children with Sensorineural Hearing Loss and Auditory Neuropathy Spectrum Disorder Fitted with Hearing Aids and Cochlear Implants. Clin. Neurophysiol. 2014, 125, 1459-1470. [CrossRef]

18. Chatterjee, R.; Datta, A.; Sanyal, D.K. Ensemble Learning Approach to Motor Imagery EEG Signal Classification. In Machine Learning in Bio-Signal Analysis and Diagnostic Imaging; Elsevier: Amsterdam, The Netherlands, 2019; pp. 183-208. ISBN 978-0-12816086-2.

19. Berger, H. Uber Das Elektrenkephalogramm Des Menschen. Eur. Arch. Psychiatr. 1929, 87, 527-570. [CrossRef] 